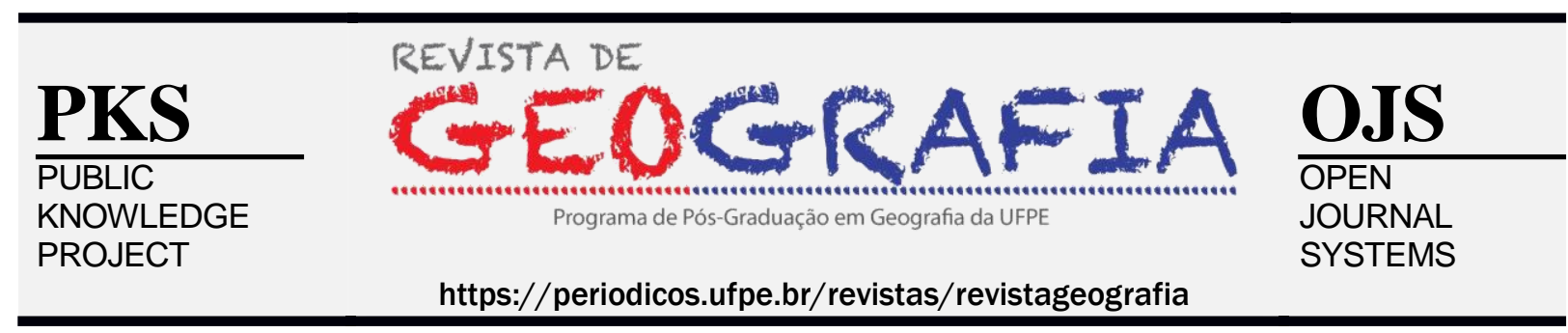

\title{
ANÁLISE DA VARIABILIDADE ESPAÇO-TEMPORAL DA PRECIPITAÇÃO NAS SUB-BACIAS DO RIO TAPEROÁ E DO ALTO CURSO DO RIO PARAÍBA
}

\author{
Daisy Beserra Lucena ${ }^{1}$, João Victor Pequeno de Oliveira², Amanda Ribeiro de \\ Andrade ${ }^{3}$, Paulo Ricardo Cavalcante de Lima $^{4}$
}

\begin{abstract}
${ }^{1}$ Graduação, mestrado e doutorado em meteorologia pela UFCG. Atualmente é professora do departamento de Geociências do centro de Ciências Exatas e da Natureza da Universidade Federal da Paraíba. daisylucena@yahoo.com.br

${ }^{2}$ Discente do curso de Engenharia Ambiental-UFPB, voluntário do Programa de Iniciação Científica (PIVIC). joao-victords@hotmail.com.

${ }^{3}$ Discente do curso de Engenharia Ambiental-UFPB, bolsista do Programa de Iniciação Científica (PIBIC). a.ribeirodandrade@gmail.com

${ }^{4}$ Discente do curso de Engenharia Ambiental-UFPB, bolsista do Programa de Iniciação Científica (PIBIC). paulo.ricardo.c.lima@gmail.com
\end{abstract}

Artigo recebido em 09/04/2018 e aceito em 23/11/2019

\begin{abstract}
RESUMO
O estudo do comportamento espacial e temporal da precipitação é de grande relevância para o mapeamento, planejamento e gerenciamento dos recursos hídricos, tendo em vista a alta variabilidade constatada na região semiárida onde está inserido o Açude Epitácio Pessoa (Boqueirão). Diante do exposto, o objetivo deste trabalho foi a análise espaço-temporal da precipitação nas sub-bacias hidrográficas que abastecem o Açude Epitácio Pessoa com o intuito de um conhecimento melhor de sua variabilidade. Para tanto, foram aplicados os métodos de Thiessen, da média aritmética e o traçado de isolinhas de precipitação, tendo como base dados de precipitação mensal para o período de 1970 a 2015. Os resultados corroboraram com os estudos existentes na região com relação ao total anual e ao período chuvoso (fevereiro-maio). Foi observado uma redução dos volumes pluviométricos no período mais recente (1994 a 2015), isso tanto em escala anual como no período chuvoso. Os mapas espaciais pelo método de Thiessen e das isoietas apresentaram o mesmo comportamento de aumento da precipitação de leste para oeste e também a diminuição nos períodos mais recentes.
\end{abstract}

Palavras-chave: Método de Thiessen, Método da média aritmética, Isolinhas de precipitação.

\section{ANALYSIS OF THE SPATIO-TEMPORAL VARIABILITY OF PRECIPITATION IN THE SUB-BASINS OF THE TAPEROÁ RIVER AND THE UPPER COURSE OF THE PARAÍBA RIVER}

\begin{abstract}
The study of the spatial and temporal behavior of precipitation is of great relevance for the mapping, planning and management of water resources, due to the high variability observed in the semiarid region where the Epitácio Pessoa (Boqueirão). In view of the above, the objective of this study was the spatio-temporal analysis of the precipitation in the sub-basins that supply the Epitácio Pessoa with the aim of acquiring better knowledge of its variability. The Thiessen methods, the arithmetical mean method and the tracing precipitation isolines method were applied for this purpose, based on monthly rainfall data from 1970 to 2015 . The results corroborate
\end{abstract}


the existing studies in the region regarding the annual total and the rainy season (February-May). A reduction in pluviometric volumes was observed in the most recent period (1994 to 2015), both on an annual scale and in the rainy season. The spatial maps generated by the Thiessen method and the isohyets registered the same behavior of increase of precipitation from east to west and also the decrease in the most recent periods.

Keywords: Thiessen method, Arithmetic mean method, precipitation isolines

\section{INTRODUÇÃO}

$\mathrm{Na}$ atualidade pesquisas que visem planejamento, desenvolvimento e conservação dos recursos hídricos são de grande importância, devido ao uso exacerbado dos mesmos e a falta de gestão para evitar situações de escassez local, seja qualitativa ou quantitativa (LUCAS et al., 2009). A bacia hidrográfica é o elemento essencial para o estudo do ciclo hidrológico terrestre, é nela que ocorre a captação da água decorrente da precipitação, a qual, devido a topografia converge para um único ponto saída, o exutório (COLLISCHONN; TASSI, 2008).

A precipitação é considerada uma das variáveis hidrológicas mais importante, pois a estimativa da precipitação em uma bacia explana uma noção da disponibilidade hídrica, auxiliando de diversas formas na gestão dos recursos hídricos (PAZ, 2004). E, ademais, é bom ressaltar que este elemento climático é um dos mais irregulares espacial e temporalmente, causando impactos em diversas atividades humanas (MIRANDA; PEREIRA, 2011).

Para uma boa gestão hídrica o conhecimento da hidrologia local é de grande valia pois proporciona o planejamento adequado para os múltiplos usos das águas, bem como em situações de escassez, priorizar o abastecimento da população, dentre outros, fins estes que são determinados pela Lei № 9.433 da Política Nacional de Recursos Hídricos (BRASIL, 1997). As sub-bacias do Rio Taperoá e do Alto Curso do Rio Paraíba estão localizadas no Estado da Paraíba e inseridas na região semiárida do Nordeste Brasileiro, região que sofre com secas proeminetes prejudicando fortemente o seu desenvolvimento agrário. As dificuldades em termos hídricos dessa região enaltecem ainda mais a necessidade de estudos que visem um entendimento melhor da precipitação.

Para determinar a precipitação média numa bacia hidrográfica, é necessário utilizar as observações de postos pluviométricos dentro do limite da bacia e em seu entorno (MENDONÇA et al., 2015; ONZI et al., 2014). Existem vários métodos para o cálculo da precipitação média, tais como o método da média Aritmética e o método de Thiessen (BERTONI E TUCCI, 2002). Para mapear a precipitação em uma bacia podem-se utilizar métodos de interpolação bem como os polígonos de Thiessen.

No âmbito de estudos pluviométricos os Sistemas de Informações Geográficas (SIG) tem se tornado cada vez mais um mecanismo indispensável. São formas de se trabalhar dados 
alfanuméricos, onde se pode fcilmente interrelacionar variáveis e obter diversas informações relevantes para tomadas. A possibilidade de espacializar esses resultados permite um visão mais ampla e holística dos objetos em estudo (BOSSLE, 2015).

Com base em técnicas de SIG, Braz et al. (2007) buscaram determinar qual dentre os métodos, polígonos de Thiessen, média aritmética ou interpolação, melhor representa a caracterização espaço-temporal das chuvas na bacia de Barra Seca - ES. O estudo alcançou que os métodos apresentaram resultados bem semelhantes no que tange a distribuição temporal das chuvas. Quanto à distribuição espacial os métodos de Thiessen e do interpolador IDW² apresentam resultados bem coerentes e semelhantes, porém o mais recomendado para essa região é o segundo já que, através de SIG, apresentam mapas contínuos, sendo mais interessante para visualização da dinâmica da pluviometria.

Mendonça et al. (2015) utilizaram os métodos da média aritmética e de Thiessen para determinar a pluviosidade média na sub-bacia do Rio Siriri - SE. Os métodos também apresentaram resultados semelhantes, porém o método de Thiessen apresentou valores um pouco maiores das médias, isto pode ser atribuído ao fato de que os maiores índices pluviométricos ocorreram nas áreas de maior influência na bacia, o que é levado em consideração nesse método e negligenciado no método da Média Aritmética, contudo os autores reforçam que a diferença não foi significativa. Os mesmos resultados com relação aos métodos foram encontrados em Batista e Gonçalves (2015) para a bacia hidrográfica do rio JacarecicaSE.

Galvíncio (2005) e Guedes (2011) realizaram estudos da variabilidade espaço-temporal da precipitação nas bacias hidrográficas do Rio Taperoá e na região do Alto Curso do Rio Paraíba, concluíram que a quadra chuvosa das sub-bacias compreende os meses de fevereiro a maio, tendo os seus volumes máximos entre meses de março e abril, e por fim que o comportamento da precipitação é semelhante nas duas sub-bacias. No que tange a espacialização, chegaram ao resultado de que os índices pluviométricos decrescem da porção oeste para leste da bacia. Araújo et al. (2007) obtém resultados que corroboram com os dos autores acima, e além disso, pelo método do IAC, determina anos secos e chuvosos nas subbacias.

Nesse contexto o objetivo desse estudo é contribuir para o entendimento da variabilidade espaço-temporal da precipitação nas sub-bacias do Rio Taperoá e do Alto Curso do Rio Paraíba, bacias estas que drenam água para o Açude Epitácio Pessoa.

\section{MATERIAL E MÉTODOS}




\section{1 Área de estudo}

A área de estudo, as Sub-Bacias Hidrográficas do Alto Curso do Rio Paraíba e do Rio Taperoá, está localizada entre as coordenadas $06^{\circ} 51^{\prime} 47^{\prime \prime}$ e $08^{\circ} 18^{\prime} 11^{\prime \prime}$ de latitudes sul e entre $36^{\circ} 0^{\prime} 10^{\prime \prime}$ e $37^{\circ} 21^{\prime} 23^{\prime \prime}$ de longitude oeste, faz parte do território que compreende o Sertão dos Cariris Velhos, ou Cariri, o qual possui os índices pluviométricos mais baixos de todo o estado, vegetação tímida e arbustiva que associada as condições semiáridas do clima e a geologia do solo cristalino dificultam a infiltração e o acúmulo de água no solo (LUCENA; PACHECO, 2008).

Na Figura 1 pode-se visualizar a localização e a distribuição espacial dos municípios inseridos em cada uma das sub-bacias. Na sub-bacia do Alto Curso do Rio Paraíba estão inseridos 18 municípios totais ou parcialmente, e a do Rio Taperoá engloba total ou parcialmente a área de 23 municípios. Sendo suas área respectivamente de $5.666,38 \mathrm{~km}^{2}$ e $6.717,39 \mathrm{~km}^{2}$.

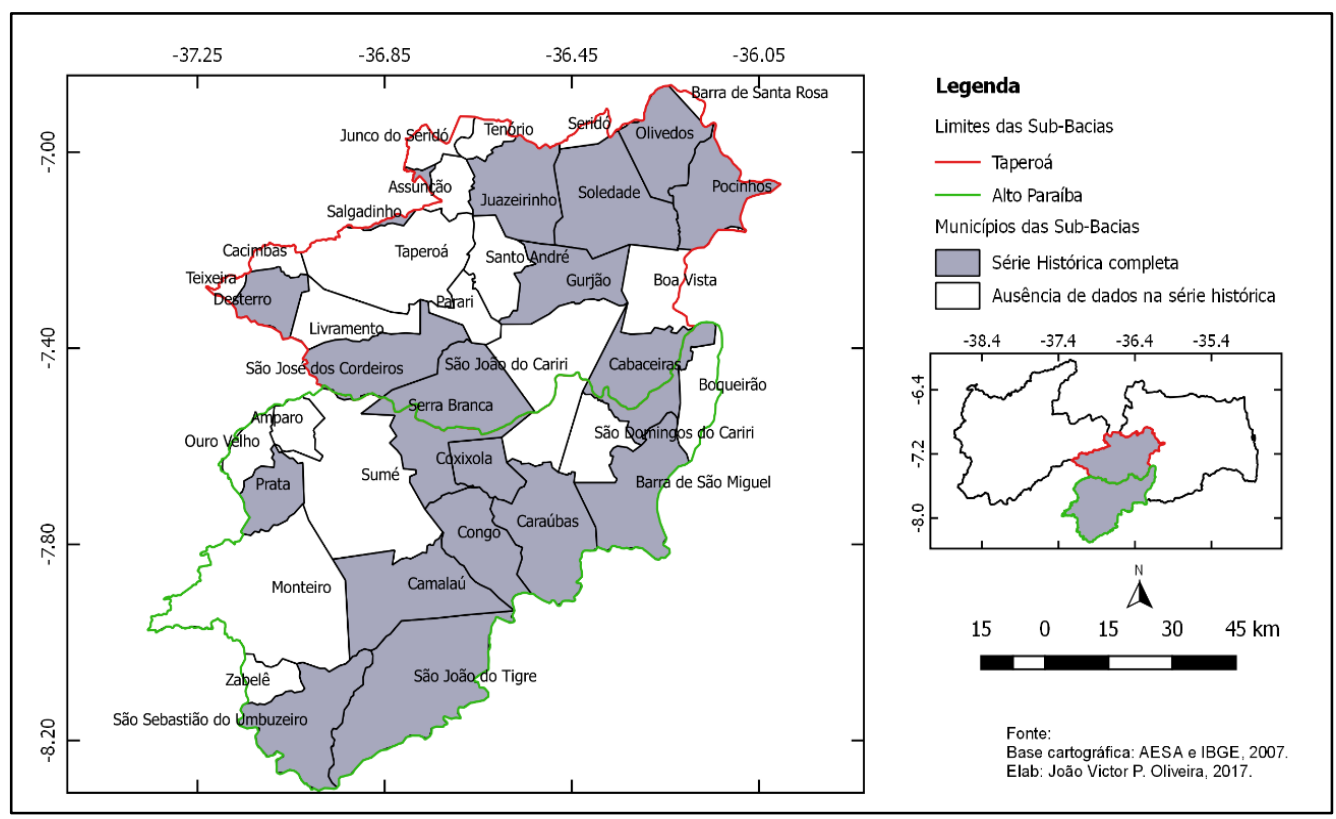

Figura 1. Localização das sub-bacias e dos municípios inseridos.

A precipitação que cai na área faz parte da rede de drenagem que abastece do Açude Epitácio Pessoa (Figura 2), sendo esse o principal reservatório pertencente a grande bacia hidrográfica do Rio Paraíba - a segunda maior do Estado da Paraíba, abrangendo 38\% do seu território (AESA, 2017; GUEDES, 2011; ARAÚJO, 2010; BARRETO et al., 2010). Este açude é considerado de suma importância para o desenvolvimento social, econômico e ambiental da 
região. Os rios e lagos do semiárido são irregulares, de características intermitentes, onde a água superficial desaparece durante o período de estiagem. A paisagem dos rios é de lagos temporários, onde a presença da água superficial é mais constante, apresenta um período de seca estacional bem marcada (GUEDES, 2011).

O açude Epitácio Pessoa, popularmente conhecido como Boqueirão, é um dos principais reservatórios do Estado, com capacidade de armazenar 411 milhões de metros cúbicos, e mesmo estando em uma das áreas mais secas de todo o país, abastece de diversas formas mais de 700 mil habitantes (MEIRA; OLIVEIRA, 2013).

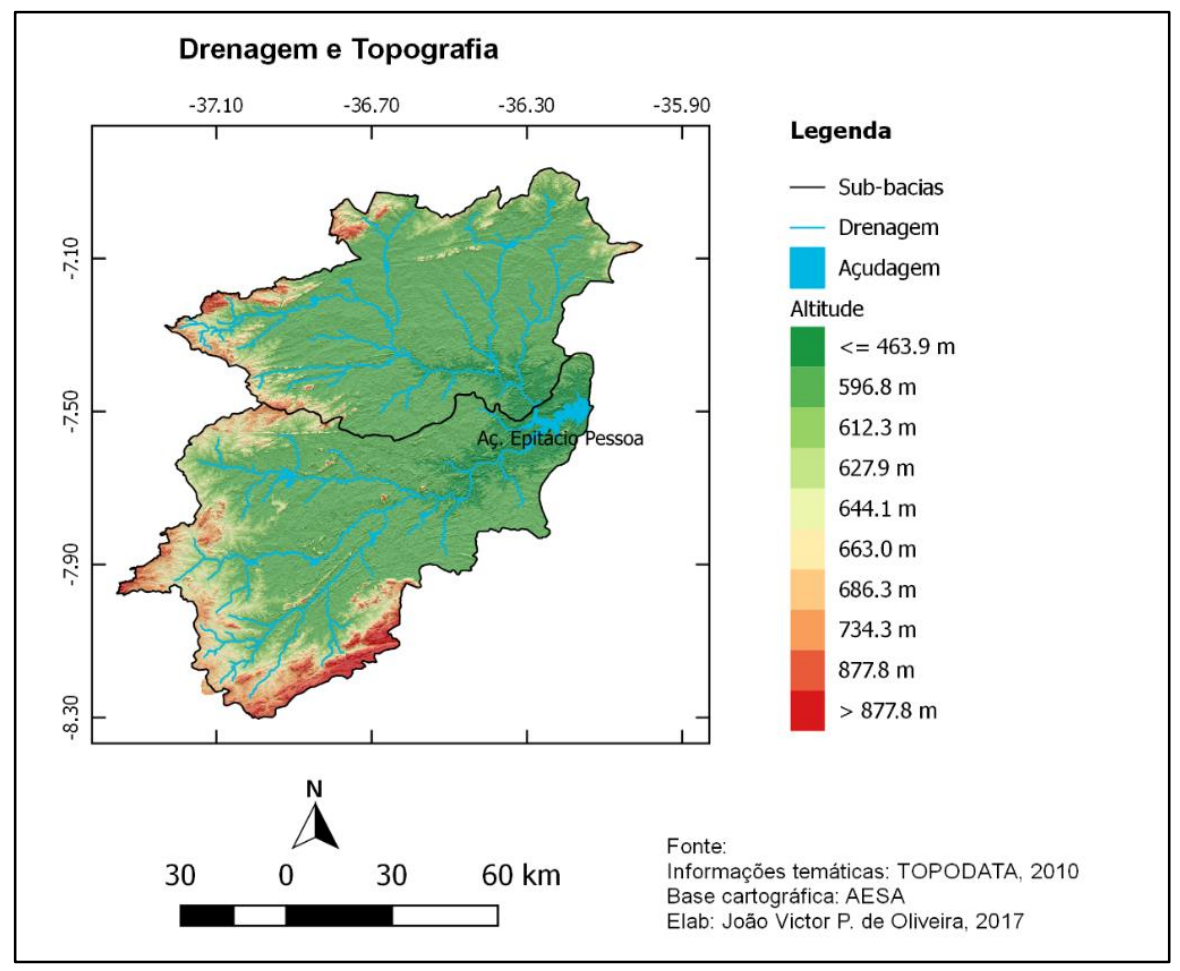

Figura 2. Drenagem e topografia das sub-bacias do Rio Taperoá e do Alto Paraíba

A base de informação dos dados de precipitação mensal para os municípios que compõe as duas sub-bacias em análise é oriunda do Departamento de Ciências Atmosféricas (DCA) da UFCG e da Agência Executiva de Gestão das Águas do Estado da Paraíba (AESA) referente ao período de 1970 a 2015. O período foi subdividido em dois devido à grande ausência de dados nos anos de 1991 a 1993. Os dois períodos serão referidos daqui em diante como "P.1" (período de 1970 a 1990) e "P.2" (de 1994 a 2015). 
Os shapefiles das sub-bacias foram adquiridos da base de dados da AESA enquanto que, os dos municípios do Instituto Brasileiro de Geografia e Estatística (IBGE). Os Rasters no Banco de Dados Geomorfométricos do Brasil - TOPODATA.

\subsection{Metodologia}

Para a análise do comportamento da precipitação nas duas sub-bacias que abastecem o Açude Epitácio Pessoa, foram realizados cálculos de média anual, mensal e para o período chuvoso utilizando de planilhas eletrônicas do software Excel e, elaborados gráficos que ilustram o comportamento anual e variação interanual da precipitação.

O cálculo da média aritmética apesar de ser um método bastante simples, uma vez que a precipitação média é obtida através da média aritmética das precipitações totais para a determinada área em um dado tempo, é bom ressaltar que este método é influenciado pelos valores extremos e apresentam-se satisfatório quando a distribuição é uniforme (CAMURÇA, 2011). Para alguns autores, esse método só apresenta boa estimativa se os pluviômetros forem distribuídos uniformemente e/ou se a área for plana com variação gradual, uma vez que o método ignora as variações geográficas da precipitação e para o cálculo, admite-se que todos os pluviômetros têm o mesmo peso (MENDONÇA et al., 2015). Contudo, é sabido que a variável precipitação apresenta muita variabilidade e na região semiárida essa é uma característica bem marcante, então, nesse contexto, aplicou-se também o método de Thiessen para verificar e comparar com o método aritmético para cada sub-bacia. O método de Thiessen é sucintamente explicado a seguir:

- Método de Thiessen: Segundo Alencoão e Pacheco (2001) e Chierice e Landim (2014) este método considera a variabilidade da distribuição espacial dos postos, mas não leva em conta o relevo da bacia. A metodologia consiste em conectar as estações por trechos retilíneos, traçando linhas perpendiculares a esses trechos passando pelo meio uma linha que liga as duas estações. As linhas perpendiculares são, então, prolongadas até encontrarem as outras. O polígono é formado pela intersecção das linhas, correspondendo à área de influência de cada estação. Partindo-se do ponto de que cada estação é representativa da área em que a altura precipitada é tida como constante, cada estação recebe um peso pela área que representa em relação à área total da bacia hidrográfica. Assim como o método aritmético, para alguns autores, este também apresenta algumas limitações, uma vez que desconsidera as influências orográficas, designando cada porção da área para estação mais próxima. Ainda assim, é considerado mais preciso que o primeiro. A precipitação média pode ser calculada através da Equação 1. 


$$
\mathrm{PM}=\left(\frac{1}{\mathrm{~A}}\right) \sum\left(\mathrm{A}_{\mathrm{i}} \cdot \mathrm{P}_{\mathrm{i}}\right)
$$

Em que PM é a precipitação média; $\mathrm{A}_{\mathrm{i}}$ é a área de influência da estação $\mathrm{i}$; $\mathrm{P}_{\mathrm{i}}$ a precipitação registrada no posto i; e A é a área total da bacia.

Este método de Thiessen, bem como a caracterização espacial da precipitação para as sub-bacias do Alto Paraíba e do Taperoá, foi realizada por meio do programa de geoprocessamento QGIS. Esse programa é um Sistema de Informação Geográfica ${ }^{1}$ (SIG) de Código Aberto licenciado segundo a Licença Pública Geral GNU. O QGIS é um projeto oficial da Open Source Geospatial Foundation (OSGeo). Funciona em Linux, Unix, Mac OSX, Windows e Android e suporta inúmeros formatos de vetores, rasters e bases de dados e funcionalidades.

\section{RESULTADOS E DISCUSSÃo}

\subsection{Distribuição temporal da precipitação nas sub-bacias}

As Figuras 3 e 4 mostram a variabilidade anual da precipitação para cada sub-bacia. Por meio das barras duplas pode-se comparar o comportamento da precipitação nos dois períodos em estudo, P.1 (1970 a 1990) e P.2(1994 a 2015). Nota-se que, como característica da área em estudo, e corroborando com outros estudos como os de Galvíncio (2005) e Guedes (2011), em ambas as bacias e nos dois períodos os meses de fevereiro a maio compreendem a quadra chuvosa. O mês de março é mais chuvoso observado, o que pode ser atribuído à Zona de Convergência Intertropical (ZCIT), sistema atmosférico que atinge seu ápice exatamente nesse período na região.

Na sub-bacia do rio Taperoá (Figura 3) a quadra chuvosa representa um percentual de aproximadamente $73 \%$ no período 1 , e $62 \%$ no período 2 , da precipitação anual, ou seja, uma redução das chuvas. É interessante observar que em maio, ao contrário dos outros meses da quadra chuvosa, tem-se um aumento significativo da precipitação. Seguindo a mesma tendência de maio, janeiro passa a ser também um mês bastante chuvoso de P.1 (28 mm de chuva) para P.2 (55,7 mm de chuva). Em contrapartida aos meses supracitados, março e abril tem uma brusca diminuição da precipitação de $18 \%$ e 39\%, respectivamente.

${ }^{1}$ DESCUBRA O QGIS. Disponível em: < http://www.qgis.org/pt_BR/site/about/index.html> 
Revista de Geografia (Recife) V. 36, No. 3, 2019

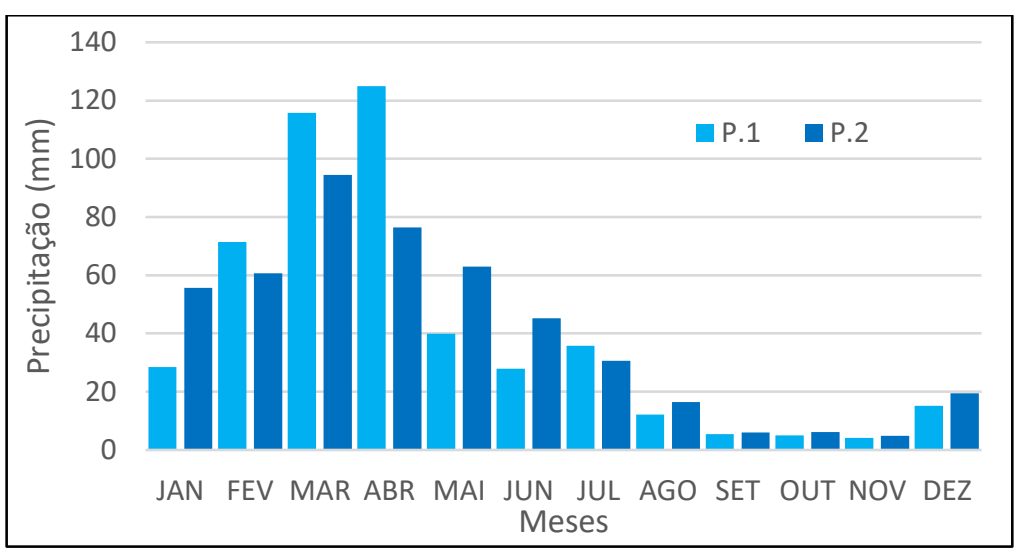

Figura 3. Variabilidade anual da precipitação na sub-bacia do Taperoá para os períodos P.1 (1970 a 1990) e P.2 (1994 a 2015)

Na sub-bacia do Alto Curso do Rio Paraíba, percebe-se também o mesmo comportamento, ou seja, a maior concentração das chuvas na quadra chuvosa e a redução em torno de $12 \%$ no período P.2. É visível na Figura 4 essa diminuição da precipitação no P.2, principalmente quando se trata dos meses mais chuvosos, fevereiro, março e abril, representando uma perda média de $101 \mathrm{~mm}$ de chuva para os referidos meses do primeiro período para o segundo. É importante ressaltar, que no período de 1970-1990 (P.1), os meses de março e abril sozinhos representam em média quase $50 \%$ de toda chuva precipitada durante o ano.

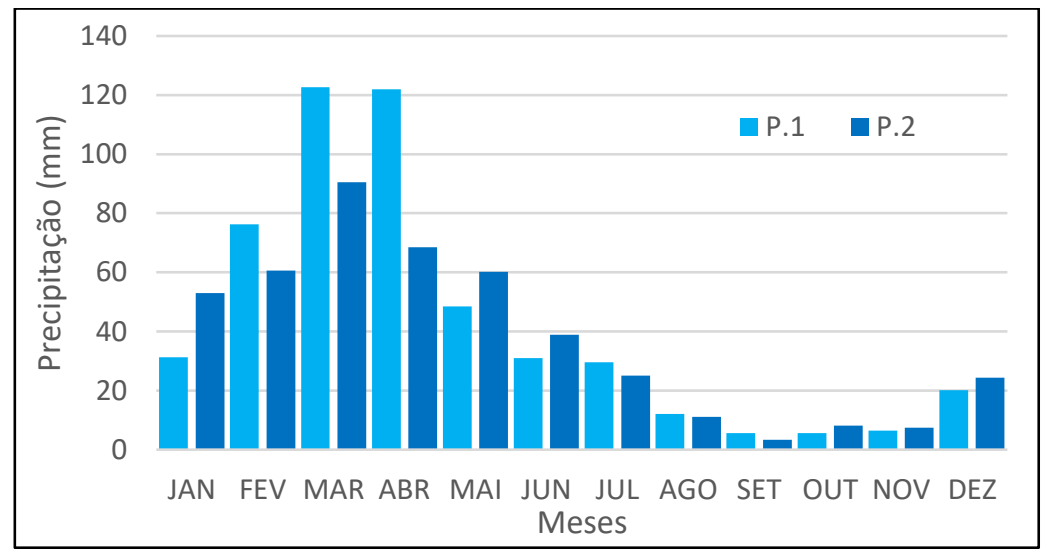

Figura 4. Variabilidade anual da precipitação na sub-bacia do alto Paraíba nos para os períodos P.1 (1970 a 1990) e P.2 (1994 a 2015)

A média da precipitação anual calculada com base nos postos pluviométricos inseridos parciais ou total dentro da bacia, para ambos os períodos bem como para o período total, pode ser visualizada na Tabela 1. O total anual médio da precipitação para as duas sub-bacias são bastante parecidos, já que estão inseridas na mesma microrregião do Cariri Paraibano. Com 
relação à comparação entre os períodos analisados verifica-se o que foi observado, na variação anual, uma queda nos volumes médios anuais. Essa diminuição foi mais intensa na sub-bacia do Alto Curso do Rio Paraíba, com diminuição em torno de 12\%. Enquanto isso, na sub-bacia do Rio Taperoá também se observa uma pequena redução que não ultrapassa $2 \%$. As médias da precipitação para o período todo, excetuando-se os períodos sem informações (1991 a 1993), são praticamente idênticas.

Tabela 1. Precipitação anual média $(\mathrm{mm})$ para as Sub-bacias

\begin{tabular}{ccc}
\hline Períodos & $\begin{array}{c}\text { Sub-bacia do Rio } \\
\text { Taperoá }\end{array}$ & $\begin{array}{c}\text { Sub-bacia do Alto } \\
\text { Curso do Rio Paraíba }\end{array}$ \\
\hline P.1 (1970-1990) & 486 & 510 \\
P.2 (1994-2015) & 478 & 450 \\
Período total (1970-2015) & 482 & 480 \\
\hline
\end{tabular}

As Figuras 5 e 6 apresenta o comportamento esperado para o semiárido, o qual possui uma alta variabilidade temporal, anos com precipitações acima e abaixo da média climatológica, não sendo visível nenhum padrão.

Entretanto, ainda nas mesmas figuras, observa-se nas sub-bacias do rio Taperoá e do Alto Curso do Rio Paraíba, períodos de estiagens como quatro anos seguidos de 1996 a 1999, por exemplo, onde o ano de 1998 apresenta os menores volumes pluviométricos de todo o período com precipitação em torno de apenas $125 \mathrm{~mm}$ anuais. E após o ano de 2011 onde, novamente, tem-se quatro anos de estiagem bem intensa, sendo 2012 um ano com índices pluviométricos bem abaixo da média. Mas, é perceptível também, que existem anos com valores acima da média como, por exemplo, o período compreendido entre 1984 e 1996 com o maior valor de precipitação anual em 1985 com aproximadamente $1050 \mathrm{~mm}$ anuais, e o período de 2008 a 2011, quatro anos com valores superiores a $580 \mathrm{~mm}$. Isso demonstra o que vários estudos têm verificado, a alta variabilidade da precipitação na região o que dificulta o prognóstico da mesma. 


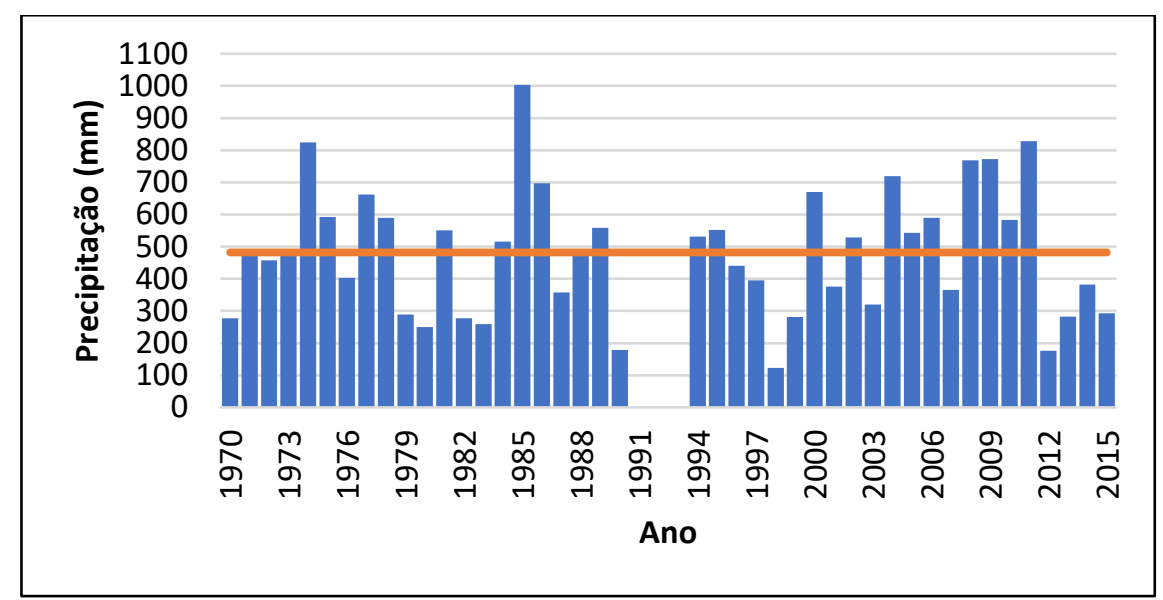

Figura 5. Variação interanual da precipitação para a sub-bacia do Taperoá (1970-2015). A linha horizontal vermelha indica o valor médio da precipitação anual para o período em estudo $(\bar{x}=482 \mathrm{~mm})$.

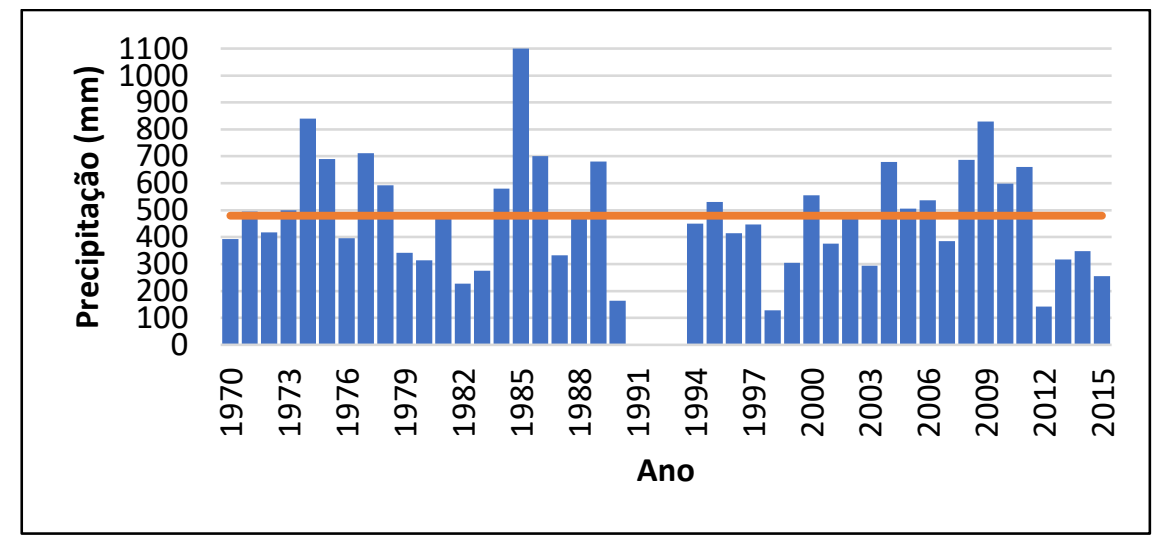

Figura 6. Variação interanual da precipitação para a sub-bacia do Alto Curso do Rio Paraíba (1970-2015). A linha horizontal vermelha indica o valor médio da precipitação anual para o período em estudo $(\bar{x}=480 \mathrm{~mm})$.

Ressaltando o ano de 2012 que foi um ano extremamente seco e causou sérios danos na região do Cariri, e no nordeste como um todo. Martins e Magalhães (2015, p.108) destrincham a problemática.

A seca plurianual iniciada em 2012, e que chegou a quatro anos de duração em 2015, é o quadriênio mais crítico em termos de totais de chuva desde 1911. Como resultado, há uma intensificação dos efeitos da seca ao longo desse período, os quais podem ser agravados ainda mais pela perspectiva de um quinto ano de seca. O Sistema Nacional de Proteção e Defesa Civil (Sinpdec) do Ministério da Integração Nacional - que se articula com os sistemas de Defesa Civil estaduais, municipais e do Distrito Federal - ocupou-se particularmente da questão do abastecimento de 
água, por meio de carros-pipa e poços. Ainda assim, faltou água para comunidades localizadas na zona rural. Ficou ainda evidente que o número de carros-pipa em atividade (contratados pelo Exército ou pela Defesa Civil Estadual) era insuficiente para atender à demanda existente em razão da intensificação do quadro crítico de 2012.

Ainda sobre a seca de 2012 no nordeste Brasileiro, Marengo et al. (2016, p. 52) mensuram sobre os prejuízos econômicos.

Uma vez que nessa região predomina a pecuária extensiva e áreas de atividade de agricultura familiar de sequeiro, a ocorrência da seca em intensidade e extensão, como a ocorrida, teve implicações na produção agropecuária. A seca de 2012- 2015 é considerada a pior nas últimas décadas, e tem se mostrado devastadora para os setores agrícola, pecuária, produtores industriais, e de acordo com o Ministério da Integração, estima-se perdas da ordem de 6 bilhões de dólares devido aos impactos da seca no setor agrícola até 2015.

A variabilidade internaual da precipitação para a sub-bacia do Alto Curso do Rio Paraíba não foi diferente, apresenta também uma alta variação e, praticamente, o mesmo comportamento. Como comentado em discussões anteriores, essa sub-bacia tem volume um pouco maior, no P.1, o que pode ser visualizado também na variação anual.

Os anos úmidos ou secos são influenciados por diversos fenômenos climáticos, em 1990, por exemplo, ocorreu-se a atuação de vórtices ciclônicos de alto nível, em 1987 o El Niño, sistemas esses que podem justificar a precipitação abaixo da média para esses anos. Já em 1984 tinha configurada uma La Niña de intensidade fraca que durou o ano inteiro, suficiente para que esse ano tivesse uma precipitação acima da média. Sobre o ano de 2004, destacado também nesse trabalho, o autor reflete sobre a relação das fortes chuvas ocorridas no estado da Paraíba, às interações de mais de um fenômeno atmosférico ocorrendo simultaneamente, nesse caso, ZCIT (Zona de Convergência Intertropical), atividades convectivas oriundas do VCANS e pela Zona de Convergência do Atlântico Sul, dando sentido para o total nesse ano ser acima da média (ARAÚJO et al., 2009).

\subsection{Comparação da precipitação média para as sub-bacias por diferentes métodos}

Como é sabido, as bacias hidrográficas contemplam uma área física delimitada pelo divisor de águas, e quando se calcula a precipitação média para a mesma baseando-se em 
média aritmética simples pode-se inferir alguns erros, já que cada posto pluviometrico possui área de influência, um peso, diferente sobre a bacia. Diante do exposto, a seguir foi realizada uma comparação do método da média com o dos polígonos de Thiessen, bastante utilizado, que não negligencia a área de influencia de cada pluviômetro na bacia e no seu entorno.

Na Figura 7 observa-se os postos pluviométricos considerados e as suas respectivas áreas de influencia, de acordo com os polígonos de Thiessen. Parte inicial importante para a realização dos cálculos do método. Yamamoto e Landim (2015) ressalvam o problema causado no limite da fronteira dos pontos de dados, onde os dados da periferia podem abrir polígonos com áreas de influência maiores que as calculadas normalmente pela meia distância entre os vizinhos mais próximos. Uma solução para isso segundo Pyrcz e Deutsch (2003), dentre outros autores, é simplesmente definir um novo limite para a área de interesse, ou seja, extrapola-la.

Diante do exposto, foram acrescentados na análise, para o método, os postos de Iguaracy/Pernambuco (ID 60), Arcoverde/Pernambuco (ID 50), Barra de Santana/Paraíba (ID 80), e Parellhas/Rio Grande do Norte (ID 40) que são municípios em que apresentam influencia sobre a região. Ressalvando-se o último posto, que não apresentou qualquer influencia, possivelmente devido à sua distância, entretanto era o posto ao norte que apresentava dados compatíveis e disponíveis para o período em estudo.

As Tabelas 2 e 3 mostram os cálculos da precipitação média para as sub-bacias considerando os métodos de Thiessen e da média aritmética. A “Área (\%)" corresponde a área percentual do polígono na sub-bacia. Para o cálculo da média pluviométrica de Taperoá e Alto Paraíba como uma única sub-bacia, foi suficiente somar a área das duas sub-bacias para a qual cada polígono teve um novo percentual de área. Na Tabela 3 observa que os postos de Serra Branca e Cabaceiras, destacados, são municípios que contribuem parcialmente para as duas sub-bacias, dessa forma foram contabilizados apenas uma vez para o cálculo da média aritmética da bacia como um todo. 


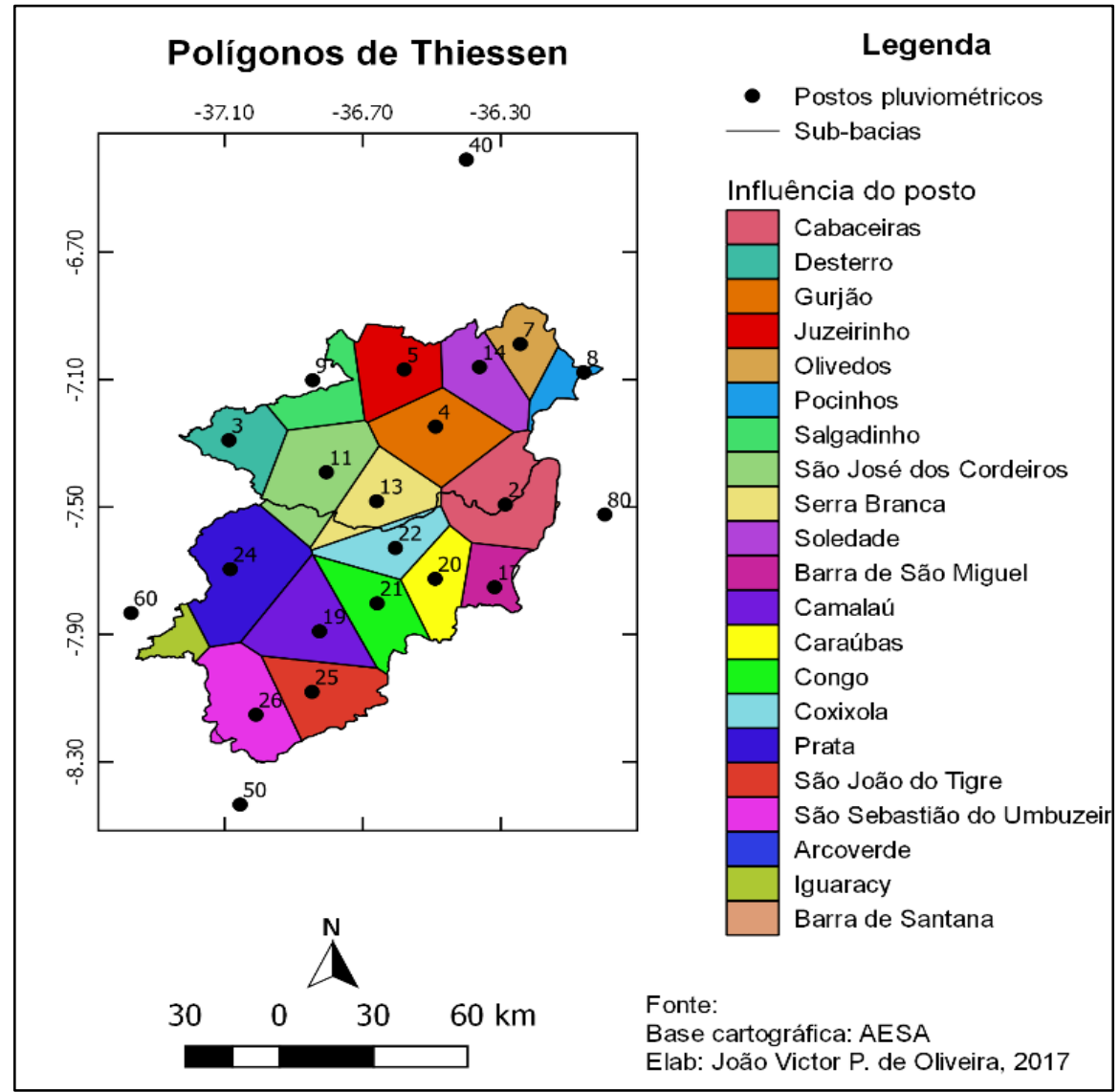

Figura 7 . Polígonos de Thiessen

Tabela 2. Dados para cálculos da precipitação média - Método de Thiessen

\begin{tabular}{|c|c|c|c|c|c|c|}
\hline \multirow[t]{2}{*}{$\begin{array}{l}\text { Sub- } \\
\text { Bacia }\end{array}$} & \multicolumn{3}{|c|}{ Posto pluviométrico } & \multicolumn{2}{|c|}{$\begin{array}{l}\text { Precipitação anual } \\
(\mathrm{mm})\end{array}$} & \multirow{2}{*}{$\begin{array}{l}\text { Área de influência } \\
\text { Área }(\%)\end{array}$} \\
\hline & ID & Município & P.1 & P.2 & Área $\left(\mathrm{m}^{2}\right)$ & \\
\hline \multirow{14}{*}{$\begin{array}{c}\text { Alto } \\
\text { Paraíba }\end{array}$} & 2 & Cabaceiras & 411,2 & 424 & 609841908,85 & 8,95 \\
\hline & 3 & Desterro & 538,6 & 630,2 & 92338,18 & 0,001 \\
\hline & 11 & São José dos Cordeiros & 530,3 & 560,5 & 167924405,66 & 2,46 \\
\hline & 13 & Serra Branca & 527,1 & 492 & 95049577,98 & 1,39 \\
\hline & 17 & Barra de São Miguel & 399 & 370 & 357297270,70 & 5,24 \\
\hline & 19 & Camalaú & 590 & 412,5 & 853772310,02 & 12,53 \\
\hline & 20 & Caraúbas & 420,5 & 374 & 543628258,64 & 7,98 \\
\hline & 21 & Congo & 547,07 & 425,5 & 665829434,89 & 9,77 \\
\hline & 22 & Coxixola & 510 & 486,54 & 511880176,78 & 7,51 \\
\hline & 24 & Prata & 651,5 & 576,7 & 1196819338,39 & 17,56 \\
\hline & 25 & São João do Tigre & 544,5 & 430 & 724425643,93 & 10,63 \\
\hline & 26 & $\begin{array}{l}\text { São Sebastião do } \\
\text { Umbuzeiro }\end{array}$ & 504,4 & 511,5 & 872216200,67 & 12,80 \\
\hline & 50 & ARCOVERDE & 691,8 & 642,3 & 641272,95 & 0,01 \\
\hline & 60 & IGUARACY & 700,7 & 534,5 & 212726034,96 & 3,12 \\
\hline
\end{tabular}


Revista de Geografia (Recife) V. 36, No. 3, 2019

\begin{tabular}{ccccccc}
80 & BARRA DE SANTANA & 542,5 & 464,05 & 3161724,01 & 0,05 \\
\hline 2 & Cabaceiras & 411,2 & 424 & 468432337,58 & 8,16 \\
3 & Desterro & 538,6 & 630,2 & 535337757,49 & 9,32 \\
& 4 & Gurjão & 456 & 468,5 & 880895223,66 & 15,34 \\
Taperoá & 5 & Juazeirinho & 460 & 494,2 & 677978359,04 & 11,81 \\
& 7 & Olivedos & 492,3 & 400,2 & 427536811,64 & 7,45 \\
& 8 & Pocinhos & 421,5 & 397,6 & 228581079,25 & 3,98 \\
& 9 & Salgadinho & 561,25 & 500,3 & 467106914,43 & 8,13 \\
& 11 & São José dos Cordeiros & 530,3 & 560,5 & 818067070,31 & 14,25 \\
13 & Serra Branca & 527,1 & 492 & 576865482,51 & 10,05 \\
14 & Soledade & 462,75 & 416,7 & 633314518,79 & 11,03 \\
22 & Coxixola & 510 & 486,54 & 28333362,35 & 0,49 \\
\hline
\end{tabular}

* Os municípios em letras maiúsculas são os postos pluviométricos fora da região em estudo (extrapolados)

Tabela 3 .Dados para cálculos da precipitação média - Método de média aritmética

\begin{tabular}{ccccc}
\hline \multirow{2}{*}{ Sub-Bacia } & & Posto pluviométrico & \multicolumn{2}{c}{ Precipitação (mm) } \\
& ID & Município & P.1 & P.2 \\
\hline \multirow{5}{*}{ ALTO PB } & 2 & Cabaceiras & 411,2 & 424 \\
& 13 & Serra Branca & 527,1 & 492 \\
& 17 & Barra de São Miguel & 399 & 370 \\
& 19 & Camalaú & 590 & 412,5 \\
& 20 & Caraúbas & 420,5 & 374 \\
& 21 & Congo & 547,07 & 425,5 \\
& 22 & Coxixola & 510 & 486,54 \\
& 24 & Prata & 651,5 & 576,7 \\
& 25 & São João do Tigre & 544,5 & 430 \\
& 26 & São Sebastião do Umbuzeiro & 504,4 & 511,5 \\
& 2 & Cabaceiras & 411,2 & 424 \\
& 3 & Desterro & 538,6 & 630,2 \\
& 4 & Gurjão & 456 & 468,5 \\
& 5 & Juazeirinho & 460 & 494,2 \\
& 5 & Olivedos & 492,3 & 400,2 \\
& 7 & Pocinhos & 421,5 & 397,6 \\
& 8 & Salgadinho & 561,25 & 500,3 \\
& 9 & São José dos Cordeiros & 530,3 & 560,5 \\
& 11 & Serra Branca & 527,1 & 492 \\
& 13 & Soledade & 462,75 & 416,7 \\
\hline 14 & & &
\end{tabular}


Para facilitar a comparação, mostra-se na tabela 4 o resumo dos cálculos para a precipitação média anual pelos métodos Polígonos de Thiessen e Média Aritmética, nos dois períodos em estudo (P.1 e P.2), para cada sub-bacia e nas duas como uma única.

As médias obtidas pelos dois métodos estão dentro do esperado para região do Cariri Paraíbano que segundo Lucena e Pacheco (2008) chove entre $350 \mathrm{~mm}$ e $700 \mathrm{~mm}$ ao ano. Através dos poligonos de Thiessen obtemos valores sempre maiores, apesar de serem discretos, isso pode ser justificado já que como o método leva em consideração a área de influência de cada postos pluviométricos, fica evidente que os municípios que apresentam maior precipitação anual, geralmente possuem também maior área de influência, como por exemplo o posto de Prata (ID 24, vide Tabela 2).

Tabela 4 . Resumo da precipitação média anual ( $\mathrm{mm}$ ) para as sub-bacias do Rio Taperoá e do Alto Curso do Rio Paraíba nos períodos 1970 a 1990 e 1994 a 2015

\begin{tabular}{ccccccc}
\hline Períodos & \multicolumn{3}{c}{ Média Aritmética } & \multicolumn{3}{c}{ Polígonos de Thiessen } \\
& Taperoá & Alto PB & Total sub-bacias & Taperoá & Alto PB & $\begin{array}{c}\text { Total sub- } \\
\text { bacias }\end{array}$ \\
\hline $\begin{array}{c}\text { P.1 } \\
(1970-1990) \\
\begin{array}{c}\text { P.2 } \\
(1994-2015)\end{array}\end{array}$ & 486 & 510 & 502 & 489 & 537 & 515 \\
\hline
\end{tabular}

\subsection{Distribuição espacial da precipitação nas sub-bacias}

A análise espacial da precipitação anual para as sub-bacias pode ser visualizada na Figura 8, e verifica-se que a porção oeste da bacia apresenta os maiores volumes de precipitação, isto observando tanto os valores pelo método de Thiessen como pelo traçado das isolinhas.

Quando se observa os períodos P.1 e P.2 é possível visualizar uma inversão da subbacia mais chuvosa do P.1, onde o Alto Paraíba apresentava maior índice pluviométrico médio anual, para o P.2, onde Taperoá apresenta um sutil aumento em relação a outra sub-bacia.

Além dessa inversão, também nota-se a diminuição dos volumes de precipitação, do primeiro perído para o subsequente, em toda bacia hidrográfica, e principalmente na região da sub-bacia do Alto Curso do Rio Paraíba. Percebe-se que no P.1 o local mais chuvso é no entorno do município de Prata, e no P.2 onde se posiciona o município de Desterro, podemos verificar esses valores também na Tabela 3 que no primeiro período analisado Prata tinha precipitação média anual de $651,5 \mathrm{~mm}$ que passa para $576,7 \mathrm{~mm}$ no segundo período estudado, 
enquanto que em desterro passa de 538,6 $\mathrm{mm}$ para $630,2 \mathrm{~mm}$, dito isso essa queda e ascenção de postos isolados por ausencia de dados em vizinhos próximos (vide Figura 1), respectivamente, mostram forte influência na espacialização.

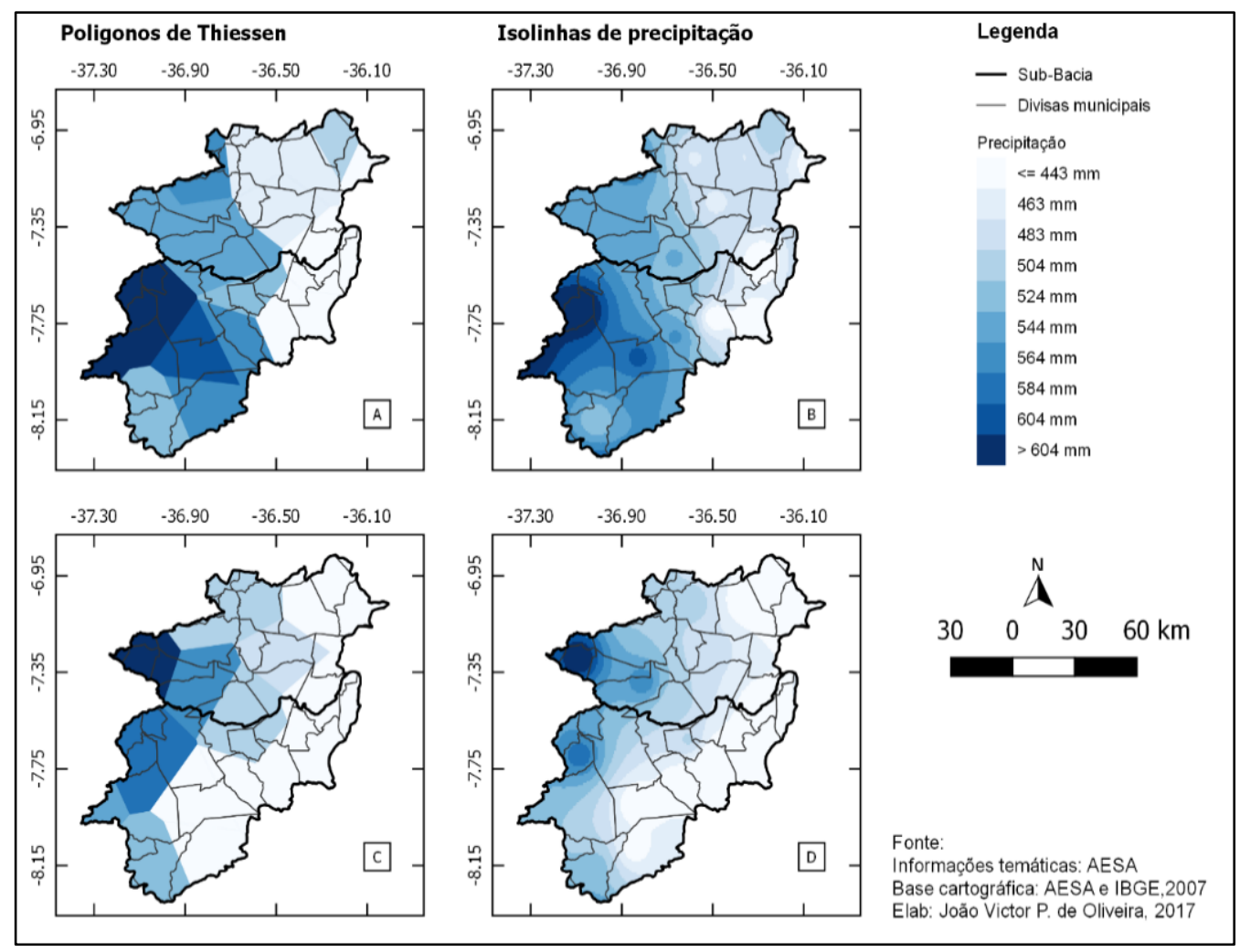

Figura 8 . Espacialização da precipitação anual pelos métodos de Thiessen (A e C) e de interpolação - isolinhas de precipitação (B e D) respectivamente para os períodos P.1 (A e B) e P.2 (C e D).

\section{CONCLUSÕES}

A problemática da má distribuição temporal e espacial das chuvas é preocupante, além de ser uma característica marcante da região do Cariri Paraibano, diante disso os resultados mostram-se interessantes para o conhecimento cada vez mais detalhado das bacias localizadas na região e que abastecem um importante açude, o Epitácio Pessoa.

A análise temporal para as duas sub-bacias em dois períodos distintos (1970 a 1990 e 1994 a 2015) mostraram que ambas apresentam o mesmo comportamento tanto na variabilidade anual quanto interanual. A quadra chuvosa, parâmetro de suma importância já que representa para essa região um grande percentual de toda precipitação anual, foi definida 
nos meses de fevereiro a maio, se mantendo a mesma para ambos os períodos. No entanto, tomando como base o período mais remoto, verificou-se uma redução de aproximadamente $12 \%$ da precipitação na quadra chuvosa. Notou-se ainda que, embora tenha sido registrada tal redução volumétrica, as chuvas mostraram-se melhores distribuídas entre os meses do ano.

A precipitação média calculada para as sub-bacias pelos métodos de Thiessen e da média aritmética apresentaram valores bem próximos, contudo os valores pelo método de Thiessen sempre maiores para as duas sub-bacias e para os dois períodos em analise, isto possivelmente está atrelado à própria metodologia que leva em consideração a área de atuação de cada posto pluviométrico, podendo ser considerado um método mais robusto.

$\mathrm{Na}$ avaliação dos métodos no mapeamento espacial, verificou-se que ambos apresentaram o mesmo comportamento, mostrando um padrão de aumento de leste-oeste. Também foi observado uma redução no período recente. No que diz respeito à espacialização, os métodos de Thiessen e IDW² mostram resultados semelhantes, todavia o interpolador IDW ${ }^{2}$ cria mapas com variações mais suaves.

\section{AGRADECIMENTOS}

O segundo e terceiro autores agradecem à UFPB juntamente ao $\mathrm{CNPq}$ (Conselho Nacional de Desenvolvimento Científico e Tecnológico) pela concessão da bolsa de Iniciação Científica. Os autores também agradecem a AESA, ao DCA e ao TOPODATA pela disponibilização de dados. E ao Qgis pela disponibilização do software.

\section{REFERÊNCIAS BIBLIOGRÁFICAS}

AESA - Agência Executiva de Gestão das Águas do Estado da Paraíba. Comitê Rio Paraíba. Disponível em: <http://www.aesa.pb.gov.br/aesa-website/comite-de-bacias/rio-paraiba/>. Acesso em: 29 Jun. 2017.

ALENCOÃO, A. M. P.; PACHECO, F. A. L. Estimativa de parâmetros hidrológicos: dois modelos, um caso de estudo. Revista da Associação Portuguesa dos Recursos Hídricos, v. 31, n. 1, p. 15-23, 2001.

ARAÚJO, L.E.; SILVA, D.J.; MORAES NETO, J.M.; SOUSA, F.A.S. Análise Da Variabilidade EspaçoTemporal Da Precipitação Na Bacia Do Rio Paraíba Usando IAC. Revista de Geografia. Recife: UFPE DCG/NAPA, v. 24, no 1, jan/abr. 2007. 
ARAÚJO, L.E. Climatologia e Vulnerabilidade Socioeconômica e Ambiental da Bacia Hidrográfica do Rio Paraíba: Estudo de caso do Açude Epitácio Pessoa (Boqueirão). Tese (Programa de Pós-Graduação em Recursos Naturais). Universidade Federal de Campina Grande. 2010.

ARAÚJO, L.E.; NETO, M.M.J.; SOUZA, S.A.F.;Classificação da precipitação anual e da quadra chuvosa da bacia do rio Paraíba utilizando o Índice De Anomalia De Chuva (IAC). Revista Ambiente \& Água - An Interdisciplinary Journal of Applied Science: v.4, n.3, 2009. BARRETO, J.F.; DANTAS NETO, J.; FARIAS, S.A.R. Avaliação socioeconômica e hídrica dos municípios da sub-bacia hidrográfica do rio Taperoá, PB. Qualit@s Revista Eletrônica. v.9. n.1. 2010.

BATISTA, L.S.; GONÇALVES, A.A. Precipitação pluviométrica da bacia hidrográfica do Rio Jacarecica. In: XXV - CONIRD - Congresso Nacional de Irrigação e Drenagem. São Cristóvão- SE. 2015.

BERTONI, J.C.; TUCCI, C.E.M. Precipitação. In: TUCCI, C.E.M. (Org.). Hidrologia: ciência e aplicação. 3.ed. Porto Alegre: Ed. Universidade/UFRGS: ABRH, 2002.

BOSSLE, R.C. QGIS e o geoprocessamento na prática. São José dos Pinhais: Edição do autor, 2015. 232p.

BRASIL. Lei $n^{\circ}$ 9433, de 08 de janeiro de 1997. Institui a Política Nacional de Recursos Hídricos, cria o Sistema Nacional de Gerenciamento de Recursos Hídricos, regulamenta o inciso XIX do art. 21 da Constituição Federal, e altera o art. $1^{\circ}$ da Lei $\mathbf{n}^{\circ} 8.001$, de 13 de março de 1990, que modificou a Lei no 7.990, de 28 de dezembro de 1989. Brasília, 1997. Disponível em: < http://www.planalto.gov.br/ccivil_03/Leis/L9433.htm>. Acesso em: 29 Jun. 2017.

BRAZ, R. L.; RIBEIRO, C.A.D.; FERREIRA, D.S.; CECÍLIO, R.A. Uso de séries históricas e técnicas de SIG no estudo da distribuição temporal e espacial da pluviosidade na Bacia Barra Seca localizada ao norte do Estado do Espírito Santo. In: XI Encontro Latino Americano de Iniciação Científica e VII Encontro Latino Americano de Pós-Graduação - Universidade do Vale do Paraíba. 2007.

CAMURÇA, P.J. Cálculo da precipitação média de forma automática pelo método de Thiessen e avaliação da precipitação na Bacia do Jaguaribe. Monografia. Universidade Estadual do Ceará. 2011.

COLLISCHONN, W.; TASSI, R. Introduzindo Hidrologia. Instituto de Pesquísas Hidráulicas da Universidade Federal do Rio Grande do Sul, Rio Grande do Sul. 2008. 149 p. 
CHIERICE, R.A.F.; LANDIM, P.M.B. Variabilidade espacial e temporal de precipitação pluviométrica na bacia hidrográfica do rio Mogi Guaçu. Geociências, v. 33, n. 1, p. 157-171, 2014.

GAlVÍnCIO, J. D. Balanço Hídrico À Superfície Da Bacia Hidrográfica do Açude Epitácio Pessoa Utilizando Informações Digitais do Terreno. Tese De Doutorado Em Recursos Naturais (Área De Concentração: Recursos Hídricos) - Universidade Federal de Campina Grande. Campina Grande. 2005. 154f.

GUEDES, R.V.S. Previsão de Seca Na Bacia Hidrográfica do Açude Epitácio Pessoa Com Base Em Redes Neurais Artificiais. Dissertação (Programa de Pós-Graduação em Meteorologia). Universidade Federal de Campina Grande. 2011.

LUCAS, E.W.M.; SOUSA, F.A.S.; SILVA, F.D.S.; LUCIO, P.S. Modelagem hidrológica determinística e estocástica aplicada à região hidrográfica do Xingu - Pará. Revista Brasileira de Meteorologia, v. 24, n. 3, p. 308-322, 2009.

LUCENA, R. L.; PACHECO, C. O Cariri Paraibano: aspectos geomorfológicos, climáticos e de vegetação. Universidade Federal da Paraíba. In: VIII Simpósio Brasileiro de Climatologia Geográfica. 2008.

MARENGO, J.A.; CUNHA, A.P.; ALVES, L.M. A seca de 2012-15 no semiárido do Nordeste do Brasil no contexto histórico. Climanálise. 3, 1-6. 2016.

MARTINS, E.S.P.R.; MAGALHÃES, A.R. A seca de 2012-2015 no Nordeste e seus impactos. Parcerias Estratégicas, Brasília, v.20, n.41, p. 107-128, dez. 2015.

MEIRA, M.S.; OLIVEIRA, M.D. Capacidade Pluvial Na Bacia Hidrográfica Do Açude Epitácio Pessoa E A Sua Capacidade Máxima Atual De Armazenamento De Água. Universidade Federal de Campina Grande. In: Anais Workshop Internacional sobre água no Semiárido Brasileiro, v.1, 2013, ISSN 2319-0248 disponível em: <http://www.editorarealize.com.br/revistas/aguanosemiarido/trabalhos/Modalidade_4dataho ra_09_11_2013_22_33_25_idinscrito_474_70f13b6ddc40f66d013c2d83f3e6b56b.pdf>. Acesso em: 29 Jun. 2017

MENDONÇA, M.C.S.; SENA, I.M.N.; SANTOS, M.R.A. Comparação Dos Métodos Da Média Aritmética E De Thiessen Para Determinação Da Pluviosidade Média Da Sub-Bacia do Rio Siriri. In: $2^{\circ}$ Congresso Internacional RESAG. Aracaju-SE. 2015.

MIRANDA, R.A.C.; PEREIRA, F.R. Desenvolvimento de plataforma para monitoramento "automatizado" de dados termo-pluviométricos. Geosul: v. 26, n. 52, 2011. 
ONZI, J.G.; MASCARELLO, G.P.; SEGATTO, J.; BUENO, P.F.; VARGAS.T. Monitoramento pluvial na bacia hidrográfica Taquari-Antas. In: II Congresso de Pesquisa e Extensão da FSG. Caxias do Sul - RS. 2014.

PAZ, A.R. Hidrologia Aplicada. Universidade Federal do Rio Grande do Sul, Rio Grande do Sul. 2004. 137 p.

PYRCZ, M.J.; DEUTSCH, C.V. Declustering and debiasing. Newsletter, v. 19, 2003. Disponível em: 〈http://www.gaa.org.au/pdf/DeclusterDebias-CCG.pdf〉. Acesso em: 29 jun. 2017.

YAMAMOTO, J.K.; LANDIM, P.M.B. Geoestatística: conceitos e aplicações. São Paulo: Oficina de Textos, 2013. 